\title{
Efeitos da regularização ambiental sobre o ordenamento territorial do município de Bagre, Marajó, Pará, Brasil
}

\author{
Fernanda do Socorro Ferreira Senra Antelo ${ }^{1}$ \\ Carlos Augusto Pantoja Ramos ${ }^{2}$ \\ Yara dos Santos Monteiro ${ }^{3}$ \\ Alynne Regina Nazaré Alves Maciel ${ }^{4}$
}

\begin{abstract}
RESUMO: Este artigo aborda a emergência recente dos temas da gestão florestal e da regularidade ambiental como problemas públicos e a inclusão destes na agenda de políticas públicas brasileiras por meio das leis federais no. 11.284/2006 e 12.651/2012. Trata-se de um estudo de caso exploratório que articula pesquisa bibliográfica e documental, bem como pesquisa-ação em processos de regularização fundiária e ambiental no intuito de: i) compreender o contexto de "caos fundiário" existente na Amazônia Legal, que ajudou a levar os temas da regularidade fundiária e ambiental ao topo da agenda de políticas públicas; ii) identificar algumas ideias institucionalizadas pelas políticas públicas supramencionadas; iii) mapear conflitos existentes entre entendimentos, diretrizes e objetivos desses marcos legislativos; e iv) apresentar dados preliminares relativos a execução do Cadastro Ambiental Rural no território paraense em geral, e no marajoara em particular. Como resultados deste artigo, conclui-se pela persistência da lógica da apropriação ilegal das terras e dos recursos florestais do Marajó por alguns segmentos econômicos, a qual é facilitada pela dificuldade de acompanhamento dos processos de cadastro pelos órgãos governamentais e pela sociedade civil.
\end{abstract}

Palavras-Chave: Políticas Públicas. Gestão Florestal. Regularidade Ambiental. Marajó, Bagre.

\section{EFFECTS OF ENVIRONMENTAL REgULARIZATION ON LAND USE PLANNING IN THE MUNICIPALITY OF Bagre, Marajó, Pará, Brazil}

Abstract: This article addresses the recent emergence of forest management and environmental regularity themes, as public problems and their inclusion in the Brazilian public policy agenda through federal laws no. $11.284 / 2006$ and $12.651 / 2012$. This is an exploratory case study that articulates bibliographic and documentary research, as well as action research in land and environmental regularization processes in order to: i) understand the context of "land chaos" existing in the Legal Amazon, which helped to take issues of land and environmental

\footnotetext{
${ }^{1}$ Bacharel e Licenciada Plena em Geografia pela Universidade Federal do Pará (UFPA), Doutora e Mestre em Ciências Sociais em Desenvolvimento, Agricultura e Sociedade pela Universidade Federal Rural do Rio de Janeiro (CPDA/UFRRJ), e integrante do Grupo de Pesquisa Mudança Social, Agronegócio e Políticas Públicas sediado nessa instituição (GEMAP/ CPDA/UFRRJ). E-mail: icamiaba@gmail.com

${ }^{2}$ Engenheiro florestal pela Faculdade de Ciências Agrárias do Pará FCAP (atual Universidade Federal Rural da Amazônia UFRA), Mestre em Ciências Florestais também pela UFRA, Assessor da Federação dos Trabalhadoras na Agricultura do Estado do Pará (FETAGRI) - Regional Marajó, e consultor ecossocial. E-mail: pantojaramos@gmail.com

${ }^{3}$ Engenheira florestal pela UFRA, Discente do Curso de Especialização em Gestão Ambiental da Universidade do Norte do Paraná (UNOPAR). E-mail: monteiroyara05@gmail.com

${ }^{4}$ Engenheira florestal e Mestranda em Biotecnologia Aplicada à Agropecuária pela UFRA. E-mail:alynnemaciel10@gmail.com
} 
regularity to the top of the public policy agenda; ii) identify some ideas institutionalized by the aforementioned public policies; iii) mapping existing conflicts between understandings, guidelines and objectives of these legislative frameworks; and iv) present preliminary data related to the execution of the Rural Environmental Registry in the Pará territory, in general, and in Marajoara, in particular. As a result of this article, it is concluded that the logic of illegal appropriation of lands and forest resources in Marajó by some economic segments persists, which is facilitated by registration processes monitoring difficulty by government agencies and civil society.

Keywords: Public Policies. Forest Management. Environmental Regularity. Marajó. Bagre.

\section{INTRODUÇão}

Com a publicação da Lei no. 12.651, de 25 de maio de 2012 冈 conhecida como novo Código Florestal, instituiu-se um novo marco regulatório sobre a proteção dos recursos naturais e o combate ao desmatamento, e que vem influenciando decisivamente no uso das florestas e a produção agropecuária nacional. Nesse sentido, o novo Código Florestal (NCF), portanto, selaria um novo pacto entre a sociedade brasileira em torno dos usos da vegetação dos distintos biomas brasileiros.

Um dos principais instrumentos de controle para obtenção de regularidade ambiental e direcionamento para programas de recuperação de áreas desmatadas é o Cadastro Ambiental Rural (CAR), registro eletrônico que possui informações georreferenciadas do imóvel rural e que atualmente é realizada por meio de autodeclarações no Sistema Nacional de Cadastro Ambiental Rural (SICAR), gerenciado nacionalmente pelo Serviço Florestal Brasileiro (SFB), órgão vinculado ao Ministério do Meio Ambiente - MMA (BRASIL, 2016).

O Pará - por meio da Secretaria Estadual de Meio Ambiente e Sustentabilidade (SEMAS)- foi um dos estados pioneiros na instituição de sistema autônomo de cadastro e monitoramento ambiental (SILVA, 2015), o qual partir de 2016 foi integrado a plataforma nacional coordenada pelo SFB.

No Marajó - localizado no estuário do rio Amazonas, com uma área de 10,2 milhões de hectares - que, no período recente, foi alvo de ações de ordenamento fundiário realizadas sobre $47,5 \%$ de suas áreas habitáveis (RAMOS; FERREIRA; COSTA, 2020), a demanda pelo CAR também aumentou muito nos últimos anos, sobretudo pela obrigatoriedade deste instrumento para a obtenção da regularidade ambiental dos imóveis e pela facilitação do licenciamento de atividades econômicas em caso de realização desse cadastramento. 
Este artigo busca identificar e caracterizar elementos do contexto socioeconômico que ajudaram o tema da regularidade fundiária e ambiental a serem considerados como problemas públicos, bem como levaram a instituição da LGFP e do NCF. Discute-se ainda as tensões entre as intenções presentes nesses dois instrumentos bem como as lacunas existentes, que facilitaram a ação de agentes locais que intentavam modificar o curso das ações de ordenamento territorial e fundiário que vinham sendo desenvolvidas por entes governamentais no Marajó.

Para atingir este objetivo foi realizado um estudo de caso exploratório e qualiquantitativo no município paraense de Bagre. A partir de pesquisa bibliográfica sobre o tema se buscou para entender o contexto de emergência dessas políticas e suas premissas, objetivos e instrumentos. Ademais, foi realizada ainda um levantamento em bancos de dados oficiais (SFB, no SICAR e no Portal do Sistema CAR do estado do Pará) visando identificar dados sobre os imóveis cadastrados nesses sistemas.

Além desta introdução e das considerações finais, este artigo possui mais cinco partes que procuram dar uma visão exploratória, mas quali-quantitativa sobre o tema. No primeiro tópico, discute-se brevemente a conjuntura socioeconômica que interferiu no tema do desmatamento na Amazônia Legal, e que levou a compreensão dos temas da gestão florestal e da regularidade ambiental como problemas públicos. Em seguida, de maneira sucinta, aborda-se a trajetória de algumas ideias que originaram a LGFP e o NCF, e em seguida, alguns dados relativos a execução do Cadastro Nacional de Florestas Públicas (CNFP) e do CAR no Brasil, no estado do Pará e no Marajó. Mais adiante de forma resumida são apresentados alguns resultados de uma iniciativa denominada de "Raio X do CAR", que foi capitaneada pelo Sindicato de Trabalhadores Rurais, Agricultores e Agricultoras Familiares de Bagre (STTR Bagre), no intuito de identificar e discutir conflitos entre objetivos declarados pela política de regularidade ambiental e a implementação de seus instrumentos nesse município. Por fim, problematiza-se os elementos ideacionais, institucionais e contextuais que vem favorecendo a captura do CAR por alguns atores sociais regionais.

\section{Metodologia de pesquisa}

A estratégia metodológica utilizada neste artigo foi a revisão bibliográfica de autores como: Araújo (2008), Azevedo (2009), Almeida (2010), Lins de Góis (2011), Moreira (2016), Souza Filho (2016) e Souza Filho; Sonda; Lemos (2016), seguida de análise documental (leis, decretos e normas infralegais) relativas à gestão florestal e regularização ambiental e, por fim, coleta de dados primários no Sistema de Cadastro Ambiental Rural da SEMAS do Pará por meio de procedimentos de 
pesquisa-ação.

Este recurso da pesquisa social foi empregado porque, além da compreensão de um problema do ponto de vista teórico, buscava-se também a resolução de um problema objetivo de forma cooperativa, na qual estavam envolvidos alguns autores deste artigo e participantes representativos da situação problema (THIOLLENT, 2011).

O recorte espacial da análise é o Marajó, mais especificamente o município de Bagre. De acordo com Brasil (2007c), o Marajó se constitui em uma das mais ricas regiões do país em termos de recursos hídricos e biológicos. Somando-se a porção continental à insular, o território marajoara alcança aproximadamente 102.809 $\mathrm{km}^{2}$, o que corresponde a uma área maior que oito estados brasileiros somados.

Até o ano de 2017, antes do Instituto Brasileiro de Geografia e Estatística (IBGE) modificar a sua metodologia de divisão regional do país, o Marajó era classificado em uma mesorregião homônima e subdividido em três microrregiões homogêneas: Arari (Cachoeira do Arari, Chaves, Muaná, Ponta de Pedras, Salvaterra, Santa Cruz do Arari e Soure), Portel (Bagre, Gurupá, Melgaço e Portel), e Furos de Breves (Afuá, Anajás, Breves, Curralinho e São Sebastião da Boa Vista).

A partir da nova regionalização do IBGE, o Marajó passou a ser definido como localizado na Região Intermediária de Breves, onde estão situados 16 municípios distribuídos em duas regiões intermediárias: Breves (Afuá, Anajás, Bagre, Breves, Chaves, Curralinho, Gurupá, Melgaço, Portel e São Sebastião da Boa Vista) e SoureSalvaterra (Cachoeira do Arari, Muaná, Ponta de Pedras, Salvaterra, Santa Cruz do Arari e Soure) (BRASIL, 2017).

Segundo o Censo Demográfico de 2010 (BRASIL, 2010), naquele ano, a população total do Marajó era 487.010 habitantes, o equivalente a 6,42\% da população paraense e a $0,24 \%$ do contingente populacional brasileiro. Cabe mencionar que a densidade demográfica do Marajó é bastante reduzida, representando em 2010, cerca de 4,84 habitantes $/ \mathrm{km}^{2}$, sendo cerca de $20 \%$ inferior a média paraense $(6,07 \%)$, levemente superior a média da Região Norte $(4,12 \%)$ e um pouco maior do que $1 / 5$ da média nacional (22,43\%). A taxa de urbanização é igualmente baixa, condizente com a estrutura econômica reduzida e essencialmente primária, representando apenas $43,82 \%$ em 2010, ou pouco mais da metade da média nacional (81\%). Dos dezesseis municípios marajoaras, apenas três (Breves, Soure e Salvaterra) possuem população urbana superior à rural:

De acordo com Euler e Ramos (2021), nos últimos anos cerca de 43\% do território marajoara foi destinado à reforma agrária, beneficiando aproximadamente 27 mil famílias e gerando ocupações para mais de 90 mil pessoas. Apesar disso, a maioria das famílias incluídas na lista de beneficiários do Programa Nacional de Reforma Agrária (PNRA) ainda não teve acesso aos auxílios para instalação 
e desenvolvimento de atividades produtiva: tais como: Contrato de Concessão de Direito Real de Uso (CCDRU), crédito instalação, fomento produtivo, auxílio habitacional, assistência técnica e extensão rural, crédito rural, etc.

Desde 2018, o Marajó está inserido no Sítio Internacional RAMSAR Estuário Amazônico e seus manguezais, que significa que essa região por suas características úmidas é objeto de tratado de cooperação intergovernamental que prevê prioridade de acesso aos apoios financeiros necessários a promoção de projetos de proteção ambiental e utilização sustentável dos seus recursos naturais (EULER; RAMOS, 2021).

O município de Bagre, recriado por meio da Lei estadual n⿳o. 2.460, de 29 de dezembro de 1961, possui área total de 4.397,321 Km² e densidade demográfica de 5,43 hab/ $\mathrm{Km}^{2}$ (BRASIL, 2010). Seus limites geográficos são: ao Norte, Breves e Curralinho; ao Sul, Portel e Baião; ao Leste, Oeiras do Pará e Baião; e a Oeste, Portel (PARÁ, 2015).

Bagre possui uma cobertura vegetal representada principalmente pela Floresta Densa dos baixos platôs. Ao longo da margem do rio Pará e do baixo curso dos seus afluentes, encontra-se a Floresta Densa da planície aluvial, da sub-região dos furos de Marajó, com intensa presença de palmeiras, principalmente do açaizeiro. De acordo com o MapBiomas (2019) e Ramos et. al (2020), esse município tem 91\% de seu território formado por florestas; $0,7 \%$ de campos naturais; 5,8\% de corpos d'água e $2 \%$ de áreas desmatadas.

No que se refere ao ordenamento territorial e fundiário, Bagre possui apenas $39.869,91$ ha (ou 9,1\%) do seu território destinado. A este respeito, destaca-se a criação de nove assentamentos rurais pelo Instituto Nacional de Colonização e Reforma Agrária (Incra) no ano de 2008. Todos na modalidade Projeto de Assentamento Agroextrativista (PAE), que é uma tipologia de assentamento destinada a proteger os direitos legais das populações que vivem em áreas abundantes em recursos extrativistas, mas cuja dispersão não está restrita a limites espaciais rígidos. Nesse município, eles ocupam uma área total de 32.207,1432 ha, possuem capacidade para atender 825 famílias tradicionais e contam com 756 famílias na relação de beneficiários do Incra, conforme tabela 1, abaixo:

No território de Bagre pode ser identificado também a existência de quatro comunidades remanescentes de quilombolas (CRQs): Ajará, Boa Esperança, São Sebastião e Tatiquara, que receberam um Título de Reconhecimento de Domínio Coletivo referente a uma área de 7.662,7691 ha, emitido pelo Instituto de Terras do Pará (Iterpa), em 2020 (PARÁ, 2020).

Conforme pode ser observado, a despeito desses esforços governamentais, ainda é significativa a porção do território que ainda não foi objeto de ações de 
ordenamento territorial e fundiário. Com isso, os moradores do Marajó com um todo, e do município de Bagre em particular, salvo exceções, são posseiros nas áreas onde realizam as suas atividades produtivas. Desse modo, nos últimos anos, essa região tem sido alvo de inúmeras tentativas de grilagem de terras e intimidação de moradores locais tanto por empresas quanto por pessoas não moradoras da região. Estes se utilizam de diversos mecanismos para atingir seus objetivos, inclusive de instrumentos que foram concebidos visando promover a regularidade ambiental de imóveis rurais, tais como o CAR (MOREIRA, 2016; CAMPELO, 2017; 2018). Problemático também é o avanço do desmatamento nessa região. Segundo o MapBiomas Alerta (2021), entre outubro de 2018 e abril de 2021, foram identificados 138 focos de desmatamento que somam 679 ha, em velocidade média de 1 ha/dia.

Tabela 1- Assentamentos de reforma agrária no município de Bagre, Pará.

\begin{tabular}{|ccccc|}
\hline No. & Nome do Assentamento & Capacidade & No.famílias assentadas & Área (ha) \\
\hline 1 & PAE Ilha Cararuá-Grande & 130 & 130 & $7.166,5446$ \\
\hline 2 & PAE Luz da Vida & 125 & 112 & $3.647,9936$ \\
\hline 3 & PAE Ilha Jurupari & 60 & 60 & $4.373,7272$ \\
\hline 4 & PAE Ilha Taquari & 80 & 80 & $6.742,7637$ \\
\hline 5 & PAE Ilha Itapera & 120 & 120 & $5.817,3259$ \\
\hline 6 & PAE Ilha Piraruaia & 60 & 60 & 600,5505 \\
\hline 7 & PAE Ilha Óias & 80 & 59 & 297,4291 \\
\hline 8 & PAE Ilha do Cabo Dico & 50 & 40 & 554,1155 \\
\hline 9 & PAE Tiririca & 100 & 95 & $3.006,6931$ \\
\hline Total & 9 & $\mathbf{8 2 5}$ & $\mathbf{7 5 6}$ & $32.207,1432$ \\
\hline
\end{tabular}

Fonte: elaboração própria a partir de dados de INCRA, 2021.

Considerando que o município de Bagre possui como principal atividade econômica o extrativismo vegetal, representado pela extração e comércio de madeiras em toras e o açaí. E que, além destes, destacam-se ainda a agricultura de subsistência e a pesca (BRASIL, 2019), todas atividades altamente dependentes da qualidade dos recursos naturais. Observando ainda que, esse município se encontra localizado uma das regiões com maior quantitativo de pessoas vivendo em situações de pobreza e extrema pobreza do estado do Pará (EULER; RAMOS, 2021), grande parte delas ainda muito dependentes de políticas governamentais de transferência direta de renda, como o Programa Bolsa Família (PBF) (BARBOSA, 2016), torna-se importante analisar esforços de gestão florestal e regularização ambiental que foram desenvolvidos nos últimos anos, bem como seus efeitos sobre o território marajoara. 


\section{O “CAOS FUNdiÁrio” E A EMERGÊnCIA DA AGENDA DE REgULARIDADE} FUNDIÁRIA E AMBIENTAL

Em meados de 2003, o tema da acelerada mudança no uso e cobertura do solo na Amazônia Legal catalisou as atenções da opinião pública e transformou o combate ao desmatamento nessa região na principal ação ambiental do governo Lula. Isto, de um lado, deveu-se a ascensão em nível federal de um governo com um projeto "democrático popular", o qual contava com a participação em vários escalões de dirigentes e lideranças dos movimentos sociais e do socioambientalismo brasileiro. Por outro lado, a divulgação pelo Instituto Nacional de Pesquisas Espaciais (Inpe), indicavam um crescimento de aproximadamente $19 \%$ no desmatamento da região no período de agosto de 2001 e julho de 2002. A divulgação destes índices elevados em um momento de contração econômica combinado a percepção quanto a sua tendência inercial, fez com que os gestores públicos passassem a reconhecer este como um problema para o qual deveriam ser apresentadas soluções governamentais (ANTELO, 2018).

A partir da publicação do Plano de Ação para Prevenção e Controle do Desmatamento na. Amazônia Legal (PPCDAm), o governo federal propôs o enfrentamento do problema do desmatamento na região por meio da aplicação de medidas de monitoramento e controle ambiental, mas, sobretudo, pelo desenvolvimento de ações interdisciplinares e estruturantes voltadas ao ordenamento territorial e ao fomento da produção sustentável. Nessa esteira, ministérios mais diretamente envolvidos com a temática ambiental e fundiária, como os do Meio Ambiente (MMA) e do Desenvolvimento Agrário (MDA), anunciaram medidas que tiveram grandes implicações sobre o ordenamento regional (ANTELO, 2018).

Uma delas foi a expedição da Portaria Conjunta Incra/MDA no. 10/2004, que suspendeu a emissão das declarações de posses e estabeleceu a obrigatoriedade da apresentação dos documentos legitimadores dos imóveis rurais em situação de posse por simples ocupação, em municípios selecionados da Amazônia Legal, sob pena de bloqueio do registro do imóvel. Ainda que esses documentos cadastrais não possuíssem qualquer amparo legal como prova de domínio, até então, eles eram utilizados em um amplo leque de operações na região, tais como: autorizações de desmatamento, planos de manejo florestal e operações de crédito rural, bem como dificultavam a realização de qualquer processo de ordenamento territorial e fundiário (ANTELO, 2018).

Em dezembro de 2007, como efeito de um novo repique nos índices de desmatamento na Amazônia, o MMA editou o Decreto n‥ 6.321 a partir do qual intentou passar de uma estratégia generalizante de combate ao desmatamento para o controle do uso do solo em pontos críticos sob os quais passam a incidir ações 
mais rigorosas de controle da degradação ambiental, tais como: i) a publicização de municípios prioritários para intensificação de ações combate ao desmatamento nesse bioma ; ii) a obrigatoriedade do recadastramento das imóveis rurais localizados em municípios com maior índice de desmatamento; iii) o controle sobre a destinação do crédito oficial; iv) autorização para o embargo compulsório de áreas desmatadas ilegalmente, exceto aquelas destinadas a subsistência; e, v) o controle das cadeias produtivas pela corresponsabilização dos compradores de produtos oriundos de áreas embargadas por desmatamento ilegal. Referenciada nestes dispositivos, foi publicada ainda a Resolução no 3.545/2008 do Banco Central (Bacen), que estabeleceu critérios ambientais para as operações de crédito na Amazônia. A partir dessa norma, a concessão de crédito rural para atividades agropecuárias em municípios do bioma passou a ser condicionada à apresentação de documentos atestando regularidade fundiária e ambiental do imóvel alvo de financiamento. Outro desdobramento legal importante, foi o Decreto no. 6.514/2008, que regulamentou da Lei de Crimes Ambientais, determinando a punição na forma de advertência e multa de proprietários que não realizassem a averbação de suas áreas de Reserva Legal (RL) em um prazo de até 180 dias (ANTELO, 2018).

Com a invalidação das reivindicações de direito, licenças e transações assentadas em documentos precários, muitos planos de manejo florestal que vinham sendo executados foram suspensos e a aprovação de novos planos passou também a ser condicionada à apresentação de títulos de domínio pelos requerentes (ANTELO, 2018). Além disso, devido as pendências fundiárias, ocupantes de terras públicas passaram a não conseguir obter licenças ambientais para exploração e comercialização legal de produtos e serviços da floresta que implicou na paralisação das atividades da indústria madeireira no estado do Pará (LINS DE GÓIS, 2011).

Estas tentativas impor limites ao avanço de algumas atividades econômicas acabaram por impulsionar mobilizações de alguns segmentos no intuito de remover marcos jurídicos formais que consistiam em obstáculos à ampliação dos espaços produtivos do chamado agronegócio (ALMEIDA, 2010). Na ocasião, governadores e prefeitos da região e alguns pesquisadores, burocratas, assessores parlamentares, analistas de grupos de interesses, etc. apontaram a regularização fundiária e ambiental como prioritários para o desenvolvimento regional e buscaram propor medidas para flexibilização de regras fundiárias e ambientais.

Como efeito dessa movimentação nos anos seguintes foram aprovadas várias normas com o intuito de regular as questões fundiária e ambiental, dentre as quais se destacam: a Lei n⿳‥ 11.284/2006, que dispõe sobre a gestão de florestas públicas para a produção sustentável (BRASIL, 2006); a Lei ํㅡ. 11.952/2009, que instituiu uma ambiciosa política federal de regularização fundiária de ocupações de até 15 
módulos fiscais localizadas em terras públicas na Amazônia Legal (BRASIL, 2009b); e anos depois foi instituída ainda a Lei no. 12.651/2012, que estabeleceu o NCF, que define novas regras para proteção da vegetação nativa nos distintos biomas brasileiros (BRASIL, 2012b).

\section{Ideias institucionalizadas: Lei de Gestão de Florestas Públicas e} novo Código Florestal

A ideia básica que orientou o Projeto de Lei (PL) nº. 4.776/2005, que originou a Lei no. 11.284/2006 (de LGFP), foi a do estabelecimento de uma base normativa para regulamentação de três formas de gestão de áreas florestadas nos biomas brasileiros: a) a criação de florestas nacionais, estaduais e municipais, nos termos da Lei $n^{\circ}$. 9.985/2000, e sua gestão direta; b) a destinação de florestas públicas às comunidades locais; e, c) a concessão florestal, incluindo florestas naturais ou plantadas e as unidades de manejo das Flonas supramencionadas na proposição (LINS DE GÓIS, 2011).

Durante sua tramitação, este PL conseguiu angariar apoios de setores distintos e antagônicos, o que tornou possível o fortalecimento e a aprovação da proposta. Cabe destacar que estavam envolvidos tanto o setor madeireiro da Amazônia, que passava por uma séria crise de abastecimento, motivada pela suspensão das operações de planos de manejo em terras públicas, razão pela qual apoiou essa iniciativa legislativa; quanto várias organizações socioambientalistas de referência no país, possivelmente baseadas na constatação da inviabilidade do combate à grilagem de terras públicas e ao desmatamento ilegal apenas por meio de ferramentas tradicionais de comando e controle, sendo as concessões florestais uma forma de aplicação de instrumentos econômicos de política florestal (ARAÚJO, 2008; LINS DE GÓIS, 2011; CHULES; SCARDUA; MARTINS, 2018).

Nesta direção, a LGFP estabeleceu o regramento para concessões de florestas públicas federais a entidades privadas e da sociedade civil. Com base no Art. 3ㅜ., inciso I dessa lei, todas as florestas, naturais ou plantadas, localizadas em áreas consideradas públicas (terras indígenas, unidades de conservação, assentamentos de reforma agrária, áreas militares e terras devolutas) nos distintos biomas brasileiros, passaram a ser consideradas patrimônio do Estado (União, estados ou municípios). A partir dessa mudança normativa foi gerado um ativo florestal, que atualmente está na ordem de quase 300 milhões de ha (BRASIL, s/d), sendo passível de exploração econômica por meio direto, por concessão florestal a iniciativa privada ou ainda por destinação para uso comunitário (BRASIL, 2006).

Juntamente com a instituição do novo regime de exploração dos recursos florestais, a LGFP também criou o SFB, para gerenciar concessões no âmbito da 
União; e o Fundo Nacional de Desenvolvimento Florestal (FNDF), destinado a fomentar o desenvolvimento de atividades e instituiu, também, a gestão florestal direta pelo poder público e pelas comunidades tradicionais, que já tinham regulação própria (BRASIL, 2006).

A partir do disposto em legislação, é de responsabilidade do órgão gestor dessa política: a) organizar e manter atualizado o Cadastro-Geral de Florestas Públicas da União (CGFPU); e, b) adotar as providências necessárias interligação dos cadastros estaduais e municipais ao Cadastro Nacional de Florestas Públicas (CNFP). Este cadastro seria uma das principais ferramentas dessa legislação e uma importante fonte de informações para as situações de tomada de decisão quanto a destinação dos estoques florestais existentes durante a elaboração dos Planos Anuais de Outorga Florestal (PAOF) (BRASIL, 2006).

Posteriormente, o Decreto no. 6.063/2007, regulamentou a LGFP, reiterando o caráter do CNFP, como uma ferramenta integrada a ser gerido pelo SFB e sendo composta por bases próprias do governo federal e informações produzidas e compartilhadas pelos órgãos e entidades gestores de florestas públicas dos entes governamentais estaduais, municipais e distritais (BRASIL, 2007c).

Com base nesta construção normativa, caso devidamente implementado, o CNFP permitiria ao SFB conhecer tanto os estoques florestais existentes quanto a localização georreferenciada das áreas de florestas públicas, tais como terras indígenas, unidades de conservação de proteção integral e territórios quilombolas reconhecidos pela União, governos estaduais e municípios.

A partir de 2008 se intensificaram também no Congresso Nacional os debates em torno da elaboração do NCF brasileiro. Durante o período puderam ser observadas narrativas distintas sobre a importância das florestas e demais formas de vegetação para a estratégia de desenvolvimento. De modo geral, essas visões podem ser sintetizadas em dois pólos que se opuseram: de um lado, socioambientalistas que argumentavam que, embora o Código Florestal tivesse problemas, era fundamental avançar na sua implementação para conter o avanço do desmatamento. De outro, os ruralistas que defendiam a flexibilização desse instrumento, baseados na ideia de que ele impunha um ônus excessivo ao setor agropecuário, considerado como estratégico para o desenvolvimento nacional. Sendo que estes últimos se saíram vitoriosos dessa etapa de disputas pela agenda pública em torno das florestas brasileiras (PIRES; SAVIAN, 2016).

Originalmente, a construção desse instrumento foi inspirada na implementação do Sistema de Licenciamento Ambiental das Propriedades Rurais (SLAPR), da antiga Fundação Estadual de Meio Ambiente do estado do Mato Grosso (FEMA$\mathrm{MT}$ ), que se constituía tanto em um plataforma única de monitoramento e controle 
do desmatamento com uso de sensoriamento remoto, sistema de informações geográficas e tecnologia da informação, quanto uma estratégia de licenciamento e fiscalização de atividades indutoras da degradação ambiental nos imóveis rurais mato-grossenses (AZEVEDO, 2009).

A partir do SLAPR, era possível tanto a realização do licenciamento em propriedades rurais, que ocorria mediante o georreferenciamento do perímetro dos imóveis, com a delimitação de áreas de preservação permanentes (APPs) e reservas legais (RLs); quanto o monitoramento do desmatamento, em cada propriedade rural e no território como um todo, com base em imagens de satélite atualizadas que eram sobrepostas aos polígonos georreferenciados dos imóveis rurais licenciados. Sendo a fiscalização ambiental orientada a partir da detecção de desmatamentos irregulares nas cartas-imagens anuais (AZEVEDO, 2009; PIRES; SAVIAN, 2016).

De acordo com Azevedo (2009), a implementação deste sistema não foi acompanhada de esforço de monitoramento ambiental, fiscalização e responsabilização dos agentes do desmatamento do Mato Grosso. Desse modo, já no início da década de 2000, os estados despontaram como um dos campeões do desmatamento na Amazônia Legal. A despeito disso, segundo Packer et al. (2008, p. 4), esse sistema foi reconhecido como o "mais avançado mecanismo de controle e monitoramento de imóveis rurais no país ao conjugar a atividade de licenciamento ambiental com monitoramento de desmatamento por imagens via satélite e fiscalização".

Em paralelo a isso, outros estados amazônicos passaram a investir na instalação ou melhoria de sistemas remotos de monitoramento, licenciamento e fiscalização de atividades agropecuárias e florestais (AZEVEDO, 2009). Foi assim que, em 2004, o governo do Pará constituiu a sua Licença Ambiental Rural (LAR), um instrumento para regularizar ambientalmente produtores rurais do estado. Posteriormente, no intento de reduzir os custos e a demora observados no processo de licenciamento no Mato Grosso, o governo paraense flexibilizou a sua matriz, desvinculando a verificação do cumprimento da legislação florestal do licenciamento ambiental de atividades potencialmente poluidoras. Isto porque compreendia que nem todas as propriedades rurais deveriam ser objeto de licenciamento ambiental compulsório (PIRES; SAVIAN, 2016).

Em 2006, o Decreto estadual no 2.593, formalizou o uso do termo Cadastro Ambiental Rural, então definido como instrumento de identificação do imóvel rural, essencial para a expedição de licenças, autorizações e demais documentos de regularidade ambiental emitidos, independentemente de transferência de titularidade. Por fim, em 2008, foi publicado o Decreto estadual no. 1148, que instituiu o CAR-PA como parte da Política Estadual de Florestas e Meio Ambiente, tornando obrigatório o cadastramento de todos os imóveis rurais localizados no 
território paraense, mesmo aqueles que não tivessem qualquer atividade rural economicamente produtiva (PARÁ, 2008).

Mais ou menos no mesmo período, o governo mato-grossense modificou o antigo SLAPR assimilando a ideia de CAR, proveniente da experiência paraense, definindo-o como etapa prévia da obtenção do licenciamento ambiental. Em paralelo, estavam sendo estabelecidas negociações visando ao reconhecimento dessas iniciativas pelo MMA, o que abriu caminho para a suspensão das multas e embargos ambientais lavrados pela fiscalização ambiental (PIRES; SAVIAN, 2016).

Tanto a iniciativa mato-grossense quanto a paraense tiveram como principais apoiadores as empresas vinculadas ao chamado agronegócio da soja e organizações não governamentais socioambientalistas, que compreendiam que era necessário conciliar as atividades agropecuárias e proteção ambiental. Isto seria viabilizado a partir do desenvolvimento de sistemas de georreferenciamento que ajudariam a mapear áreas produtivas brasileiras e a demonstrar aos consumidores externos que o desenvolvimento dessas atividades econômicas não estava em conflito com os objetivos de preservação das florestas brasileiras ${ }^{5}$.

A despeito das contradições e problemas que já podiam ser identificados nesses instrumentos, em 2009, esse modelo de cadastramento ambiental obteve alcance nacional a partir da publicação do Decreto $\mathrm{n}^{\circ}$. 7.029, que instituiu o Programa Federal de Apoio à Regularização Ambiental de Imóveis Rurais (também designado como "Programa Mais Ambiente") (BRASIL, 2009a). Naquele contexto, muito embora não houvesse obrigatoriedade de participação dos estados, já havia a intenção de se estabelecer uma política nacional de regularização ambiental, que ajudasse a promover a chamada adequação ambiental da agricultura brasileira.

Nesta direção, em 2012, foi instituída a Lei no. 12.651 (BRASIL, 2012b), que revogou o antigo Código Florestal brasileiro e o substituiu por um novo que, entre outras inovações, estabeleceu o CAR, uma espécie de registro público eletrônico de âmbito nacional, obrigatório para todos os imóveis rurais e que conforma uma base de informações ambientais relativas as propriedades e posses rurais, com fins de monitoramento, planejamento ambiental e econômico e combate ao desmatamento. Posteriormente, o Decreto no. 7.830/2012 dispôs sobre o SICAR, estabelecendo normas de caráter geral aos Programas de Apoio e Incentivo à Preservação e Recuperação Ambiental (BRASIL, 2012a).

A partir dessas normatizações, o CAR possui caráter auto declaratório, e consiste no levantamento de informações georreferenciadas com o intuito de se construir um mapa digital de todos os imóveis rurais brasileiros. A partir dele poderão ser

\footnotetext{
${ }^{5}$ Como exemplo dessas iniciativas, pode ser citado um experimento com o CAR, realizado em Paragominas no estado do Pará, no intuito de promover a adequação ambiental deste município e retirá-lo da listagem de áreas com maior índice de desmatamento na Amazônia Legal, estabelecida pelo Decreto nº. 6.321/2007 (MARTINS; SOUZA Jr, 2011)
} 
obtidos e integrados dados relativos à localização e ao tamanho de propriedades ou posses, bem como informações relativas às APPs, RL, áreas remanescentes de vegetação nativa, consolidadas, e de uso restrito.

Estas estabeleceram ainda a possibilidade de suspensão de multa, sanções e embargos por desmatamento ilegal em APPs e RLs aplicadas até 22 de julho de 2008. Para solicitar essa anistia seria necessário apenas que o produtor rural realizasse o registro de seu imóvel rural no CAR e assumisse o compromisso formal de recompor áreas degradadas e preservar áreas de preservação. de reserva legal e de uso restrito do imóvel rural, ou ainda de compensar áreas de reserva legal (BRASIL, 2012a; 2012b).

Posteriormente, o MMA, por meio da Instrução Normativa (IN) no . 2/2014, estabeleceu os procedimentos para a integração, execução e compatibilização do SICAR e definiu os procedimentos gerais do CAR. De acordo com esta IN, a adesão ao CAR pode ser feita a partir de três regimes de apropriação da terra: a) imóvel rural: propriedades e posses individuais; b) imóvel rural de povos e comunidades tradicionais; e, c) imóvel rural de reforma agrária (BRASIL, 2014).

Ainda de acordo com esta IN, a inscrição e o registro do imóvel rural no CAR é gratuita e deve conter: a) identificação do proprietário ou possuidor do imóvel rural; b) comprovação da propriedade ou posse rural; e c) planta georreferenciada da área do imóvel, contendo a indicação das coordenadas geográficas, com pelo menos um ponto de amarração com o perímetro do imóvel e o perímetro das áreas de servidão administrativa (APPs, RL, áreas remanescentes de vegetação nativa, de uso restrito e consolidadas) (BRASIL, 2014).

\section{Dados preliminares do Cadastro Nacional de Florestas Públicas e do Cadastro Ambiental Rural}

De acordo com dados do CNFP, 297 milhões de hectares (ou pelo menos 35\% do território nacional) são áreas de florestas públicas, ou seja, que pertencem à União, estados, municípios ou Distrito Federal. Destes 110 milhões de ha correspondem as terras indígenas, 61 milhões são unidades de conservação federais, 41 milhões de ha são áreas destinadas estaduais, 10 milhões de ha são assentamentos de reforma agrária e mais 5 milhões de ha são áreas destinadas municipais (BRASIL, s/d).

Com a implementação do CAR, surgiu a faculdade de lançamento de dados no sistema eletrônico online por parte de proprietários e posseiros, retirando com isso a obrigatoriedade da participação de um técnico nesse registro. Como resultado disso, uma das expectativas era que o processo de licenciamento ambiental fosse mais ágil, pois a comprovação da regularidade do imóvel se daria por meio da inscrição e aprovação do CAR por um técnico e o cumprimento das condiciona- 
ntes previstas no PRA dos respectivos estados, não havendo mais a necessidade de averbação em matrícula de RL das propriedades (VIEIRA, 2019).

Esse cenário provocou uma super demanda por esse cadastramento, o que fez com que, até novembro de 2019, fossem cadastrados 58,9 milhões ha a mais do que estoque de 97,7 milhões de ha cadastráveis na Região Norte (BRASIL, 2019), conforme pode ser observado no Quadro 1, abaixo:

Quadro 1 - Áreas cadastradas no sistema CAR na Região Norte, estado do Pará, Ilha do Marajó e município de Gurupá.

\begin{tabular}{|l|l|l|l|}
\hline Área de abrangência & $\begin{array}{l}\text { Área Cadastrável } \\
\text { (ha) }\end{array}$ & $\begin{array}{l}\text { Área Cadastradas } \\
\text { (ha) }\end{array}$ & Fonte da Informação \\
\hline Brasil & 397.836 .864 & 543.032 .438 ha & Boletim SFB (2019) \\
\hline Região Norte & 93.717 .515 & 152.673 .351 & Boletim SFB (2019) \\
\hline Estado do Pará & 56.836 .278 & 71.062 .504 ha & Boletim SFB (2019) \\
\hline Ilha do Marajó & $10.408 .619,14$ & $8.111 .207,45$ & $\begin{array}{l}\text { IBGE Cidades; SICAR } \\
\text { PA (2020) }\end{array}$ \\
\hline Gurupá & $854.011,31$ & $984.423,77$ & $\begin{array}{l}\text { IBGE Cidades; SICAR } \\
\text { PA (2020) }\end{array}$ \\
\hline
\end{tabular}

Fonte: elaboração própria a partir de dados de BRASIL (2019, 2020), PARA (2020).

De acordo com dados do painel nacional sobre o CAR do SFB, até 31 de janeiro de 2020, 6,5 milhões de imóveis rurais já haviam sido cadastrados, totalizando uma área de 543.703.650,46 ha inseridos na base de dados do sistema (BRASIL, 2020), equivalente a $63 \%$ do território nacional.

Segundo o Portal do Sistema CAR do estado do Pará, informações de 7 de setembro de 2020, já haviam sido efetuados 229.755 cadastros em território paraense. Na Ilha do Marajó, com base na sistematização realizada por Ramos, Ferreira e Silva (2020), com data base de julho de 2020, haviam sido realizados 7.113 CARs, totalizando uma área de $8.111 .207,45$ ha, o que equivale a $73 \%$ do território marajoara (Tabela 2).

A partir dos dados levantados, não há dúvidas de que o sistema CAR logrou êxito em promover uma aceleração na busca pela prova de regularidade ambiental via cadastro. O que, em tese, confirmaria os propósitos de criação desse instrumento: a geração de alternativas que simplificassem e tornassem mais expedito os processos de regularização ambiental dos imóveis rurais, visto que os métodos anteriores de cadastramento apresentavam morosidade procedimental e baixo número de processos legalizados (VIEIRA, 2019).

No entanto, cabe mencionar que embora o CAR não tenha sido criado com a 
finalidade determinar o domínio da terra, em levantamento realizado no estado do Pará por Barcelos et al. (2016) foi identificado que, num universo de $150 \mathrm{mil}$ cadastros, 108 mil possuíam algum tipo de sobreposição com outra área. Além disso, na Amazônia Legal e, em particular na Ilha do Marajó, são vários os relatos de pressões sobre comunidades tradicionais, bem como de expulsões e despejos judiciais de pequenos agricultores e suas famílias a partir da utilização do CAR como documento fundiário (CAMPELO, 2017; PIRES, 2017). Estes eventos confirmam a hipótese levantada por Souza Filho et al. (2015), quanto possibilidade de uso indevido deste cadastro como prova de posse visando a legitimação da apropriação primária.

Tabela 2 - Cobertura do Cadastro Ambiental Rural nos municípios do Marajó.

\begin{tabular}{|c|c|c|c|c|}
\hline Municípios & Área Total* & $\begin{array}{l}\text { Área Coberta } \\
\text { com CAR }\end{array}$ & $\begin{array}{c}\text { Número de } \\
\text { inscrições } \\
\text { no Sistema } \\
\text { CAR }^{* *}\end{array}$ & $\begin{array}{c}\text { \% de Área } \\
\text { Municipal } \\
\text { Coberto pelo } \\
\text { CAR }\end{array}$ \\
\hline Afuá & $837.285,21$ & $797.019,56$ & 479,00 & 95,19 \\
\hline Anajás & $691.296,50$ & $428.273,13$ & 625,00 & 61,95 \\
\hline Bagre & $439.733,89$ & $290.964,89$ & 89,00 & 66,17 \\
\hline Breves & $950.899,90$ & $875.236,99$ & 410,00 & 92,04 \\
\hline $\begin{array}{l}\text { Cachoeira do } \\
\text { Arari }\end{array}$ & $310.026,42$ & $277.611,34$ & 128,00 & 89,54 \\
\hline Chaves & $1.308 .470,90$ & $741.875,87$ & 626,00 & 56,70 \\
\hline Curralinho & $361.728,20$ & $74.796,34$ & 223,00 & 20,68 \\
\hline Gurupá & $854.011,31$ & $984.423,77$ & 761,00 & 115,27 \\
\hline Melgaço & $677.400,49$ & $501.209,57$ & 55,00 & 73,99 \\
\hline Muaná & $376.332,97$ & $227.930,05$ & 497,00 & 60,57 \\
\hline $\begin{array}{l}\text { Ponta de } \\
\text { Pedras }\end{array}$ & $336.383,44$ & $244.681,55$ & 917,00 & 72,74 \\
\hline Portel & $2.538 .510,63$ & $2.137 .833,47$ & $1.990,00$ & 84,22 \\
\hline Salvaterra & $103.904,75$ & $49.969,25$ & 62,00 & 48,09 \\
\hline $\begin{array}{l}\text { Santa Cruz do } \\
\text { Arari }\end{array}$ & $107.667,19$ & $74.610,54$ & 71,00 & 69,30 \\
\hline $\begin{array}{l}\text { São Sebastião } \\
\text { da Boa Vista }\end{array}$ & $163.228,66$ & $148.047,92$ & 61,00 & 90,70 \\
\hline Soure & $351.738,68$ & $256.723,21$ & 119,00 & 72,99 \\
\hline $\begin{array}{l}\text { Total no } \\
\text { Marajó }\end{array}$ & $10.408 .619,14$ & $8.111 .207,45$ & $7.113,00$ & \\
\hline
\end{tabular}

Fonte: elaboração própria a partir de dados do SICAR-PA, 2020. 


\section{EFEITOS DA GESTÃo FLORESTAL E FLORESTAL SOBRE O MUNICÍPIO DE BAGRE}

No que se refere a execução do CAR nesse município, em 2017, após ter recebido inúmeros relatos da existência de inúmeros CARs sem comprovação da posse mansa e pacífica e da utilização desses cadastros para intimidar os legítimos ocupantes dessas áreas, o STTR Bagre, junto com organizações parceiras, realizou uma atividade denominada de "Raio X do CAR" no intuito de sensibilizar as comunidades locais em relação a obrigatoriedade dessa ferramenta de cadastramento ambiental e, ao mesmo tempo, verificar alguns efeitos preliminares da implementação desse instrumento sobre o territorial municipal.

Desse modo, os autores deste estudo levantaram todas informações públicas referentes aos CARs no Portal da SEMAS (Endereço: http://car.semas.pa.gov.br), tais como: a) número do recibo do CAR; b) nome e CPF do Cadastrante; c) nome e CPF do Domínio (a quem se destina o CAR); d) área em hectares declarada ${ }^{7}$, cujo resultado é apresentado de forma sincretizada nas tabelas 3 e 4 .

Conforme pode ser observado, foram identificados nove cadastros correspondentes aos assentamentos de reforma agrária criados sob jurisdição da SR-01 do Incra de Belém, que englobam 45.465,65ha ou 16,5\% da área municipal registrada no CAR.

Foram identificados ainda nesse município, 45 CAR's em nome de particulares (pessoas físicas e jurídicas), que perfazem uma área de 230.015,33 ha, correspondendo a $83,5 \%$ da área cadastrada na SEMAS-PA (Tabela 4).

Destes 45 CARs individuais, cabe destacar ainda que, se de um lado, pouco mais de $2 \%$ deles, ou seja, apenas um dos cadastros está acima da faixa de 10.000 ha e abarca mais de $65 \%$ da área de Bagre cadastrada no SICAR-PA; e outros 46,7\% estão na faixa de 500 a 1.500 ha ocupando quase $10 \%$ da área sob cadastro. Por outro lado, têm-se um cadastro coletivo de PAE com área de apenas 620,39 ha para um total de 60 famílias.

Considerando que a maioria desses cadastros, corresponde a imóveis com áreas muito acima do módulo fiscal do município de Bagre, que segundo Brasil (2013) é de 70 ha, o que sinaliza uma forte tentativa de concentração de terras e recursos naturais sob a gestão de poucos atores via CAR.

Além do levantamento de dados junto à SEMAS, em caso de incidência do CAR sobre a área dos PAEs existentes no município de Bagre foi realizada ainda a checagem se o detentor do Protocolo do CAR constava na Sistema de Informações de Projetos de Reforma Agrária (SIPRA) do Incra, qual permitiu ao STTR de Bagre verificar se os cadastros eram ou não de agricultores/agricultoras familiares desses assentamentos.

\footnotetext{
${ }^{6}$ Esta atividade foi realizada no âmbito da campanha "Não venda a sua terra, não venda a sua vida", desenvolvida pela Fetagri Pará.

${ }^{7}$ Cabe destacar que essa consulta se mostrou possível porque o Portal do CAR da Semas no estado do Pará possui uma estrutura de consulta mais aberta do que o SICAR Nacional.
} 
Nesse processo de triangulação foi possível identificar a existência de dois CARs individuais numa área total de 5.347,14 ha que se encontravam sobrepostos ao CAR do PAE Ilha Cararuá Grande, conforme pode ser observado na figura 1.

Tabela 3 - CAR sobre áreas coletivas no município de Bagre (PA).

\begin{tabular}{|c|c|c|c|c|c|}
\hline $\begin{array}{l}\text { Grupos de } \\
\text { área total }\end{array}$ & $\begin{array}{l}\mathrm{N}^{0} \text { de } \mathrm{Ca}- \\
\text { dastros }\end{array}$ & $\begin{array}{c}\% \\
\text { Cadastros }\end{array}$ & $\begin{array}{l}\text { Área } \\
\text { (ha) }\end{array}$ & $\begin{array}{l}\% \\
\text { Área }\end{array}$ & $\mathbf{N}^{0}$ Recibo CAR \\
\hline $\begin{array}{l}\text { Menos de } 100 \\
\text { ha }\end{array}$ & 0 & $0,0 \%$ & 0,00 & $0,0 \%$ & \\
\hline $\begin{array}{l}\text { De } 100 \text { a } \\
\text { menos } 500 \text { ha }\end{array}$ & 0 & $0,0 \%$ & 0,00 & $0,0 \%$ & \\
\hline $\begin{array}{l}\text { De } 500 \text { a me- } \\
\text { nos de } 1.500 \text { ha }\end{array}$ & 1 & $11,1 \%$ & 620,39 & $1,6 \%$ & $\begin{array}{l}\text { PA-1501105-89875A- } \\
\text { 7 C } 456641 \text { D } 49 \text { A - } \\
\text { 6F21BAA58B2DAD, }\end{array}$ \\
\hline $\begin{array}{l}\text { De } 1.500 \text { a } \\
\text { menos de } 2.500 \\
\text { ha }\end{array}$ & 0 & $0,0 \%$ & 0,00 & $0,0 \%$ & \\
\hline $\begin{array}{l}\text { De } 2.500 \text { a me- } \\
\text { nos de } 10.000 \\
\text { ha }\end{array}$ & 8 & $88,9 \%$ & $39.261,70$ & $98,4 \%$ & 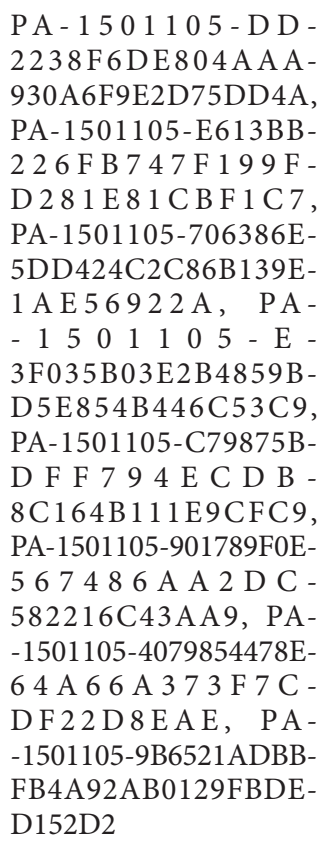 \\
\hline $\begin{array}{l}\text { De } 10.000 \text { ha a } \\
\text { mais }\end{array}$ & 0 & $0,0 \%$ & 0,00 & $0,0 \%$ & \\
\hline Total & 9 & $100,0 \%$ & $39.882,09$ & $100,0 \%$ & \\
\hline
\end{tabular}

Fonte: Elaboração própria a partir de dados do SICAR-PA. 


\section{Tabela 4 - CAR sobre áreas individuais no município de Bagre (PA).}

\begin{tabular}{|c|c|c|c|c|c|}
\hline $\begin{array}{l}\text { Grupos de } \\
\text { área total }\end{array}$ & $\begin{array}{l}\mathrm{N}^{\circ} \text { de } \\
\text { Cadastros }\end{array}$ & $\begin{array}{c}\% \\
\text { Cadastros }\end{array}$ & Área (ha) & \% Área & No Recibo CAR \\
\hline $\begin{array}{l}\text { Menos de } \\
100 \text { ha }\end{array}$ & 2 & $4,4 \%$ & 28,64 & $0,01 \%$ & $\begin{array}{l}\text { PA-1501105-EAC89AF9585C41859E } \\
\text { 9F5BFB0087D81F, PA-1501105-616B } \\
\text { F00DE0544AA39806E047EBD758A6 }\end{array}$ \\
\hline $\begin{array}{l}\text { De } 100 \text { a } \\
500 \text { ha }\end{array}$ & 8 & $17,8,2 \%$ & $2.317,00$ & $1,01 \%$ & $\begin{array}{l}\text { PA-1501105-B4D4EA7A738D46098359, PA- } \\
\text {-1501105-30454B16D18E430EBD062C6572D4B245, } \\
\text { PA-1501105-6FF7B25D336842AA90673BF64CCDAFBB, } \\
\text { PA-1501105-1F11D8079E0646679248A207367D4C9D, } \\
\text { PA-1501105-8E1BDA8DA97543579231C2F22850AB6A, } \\
\text { PA-1501105-CF4A57F7C01349D4B831FB3A51B696C7, } \\
\text { PA-1501105-E7D9971A8C07422090CA151ADC84CE43, } \\
\text { PA-1501105-020E6DEACD2A47188D69A9D7138A31D0 }\end{array}$ \\
\hline $\begin{array}{l}\text { De } 500 \text { a } \\
\text { menos de } \\
1.500 \text { ha }\end{array}$ & 21 & $46,7 \%$ & $22.864,20$ & $9,94 \%$ & $\begin{array}{l}\text { PA-1501105-4808AD0912294042A4729BB098DF9F31, } \\
\text { PA-1501105-1C36D9EDB03B427CBAE8096A9CE63589, } \\
\text { PA-1501105-C3135581FF664B5F9E109A34A78FAA5E, } \\
\text { PA-1501105-2AEA22D4E51542B1A6A8917A02E9F179, } \\
\text { PA-1501105-F16728CE879C4D4CA64CA904, PA- } \\
\text {-1501105-6285B1E0EE284ECA95658121A6DEA262, } \\
\text { PA-1501105-5D167AE72C714047A707110051B9E048, } \\
\text { PA-1501105-3EAE70A066254E02BE021C897290B6CC, } \\
\text { PA-1501105-024890120927437BAEB279BBF413F9DB, } \\
\text { PA-1501105-8B5EA48FE9C547CD9475A1FE89F2F977, } \\
\text { PA-1501105-E7A6D4A9496A4E98BEAE1067BAB8687D, } \\
\text { PA-1501105-5E95B62B0B634EE39EE8451864046E3E, } \\
\text { PA-1501105-D71CD7275A0F4108A15A- } \\
\text { D0A7F8DD1BBD, PA-1501105-668BB5DC- } \\
\text { 2C494E179853EC7B4679CE6D, PA-1501105-A- } \\
\text { D946980D9F441B198842E0D9A40A940, } \\
\text { PA-1501105-E01923D5BC01456FB99DEA- } \\
\text { CB7BF8485F, PA-1501105-CA84473F5FC34B- } \\
\text { 6DB3D60AD7AF165A9E, PA-1501105-84977E- } \\
\text { D296B94FD2A7E67728ECB7EF50, } \\
\text { PA-1501105-FA7CAC4EC1BE4CBEA3FACD45D630BCC1, } \\
\text { PA-1501105-1E38445FC87A4FBCA280EA44B7C1C1CF, } \\
\text { PA-1501105-020E6DEACD2A47188D69A9D7138A31D0 }\end{array}$ \\
\hline $\begin{array}{l}\text { De } 1.500 \text { a } \\
\text { menos de } \\
2.500 \text { ha }\end{array}$ & 6 & $13,3 \%$ & $13.984,55$ & $6,08 \%$ & $\begin{array}{l}\text { PA-1501105-06077CEFF30E4F1F83251D17EC4BBE82, } \\
\text { PA-1501105-65B82EB1950440A38FA54DA0, PA- } \\
\text {-1501105-DF7F329C9BB24926AFE7E49D42D6BF86, } \\
\text { PA-1501105-E7A6D4A9496A4E98BEAE1067BAB8687D, } \\
\text { PA-1501105-DF7F329C9BB24926AFE7E49D42D6BF86, } \\
\text { PA-1501105-121F1C8ABE3540DE9AB55DE408F8487B }\end{array}$ \\
\hline $\begin{array}{l}\text { De } 2.500 \text { a } \\
\text { menos de } \\
10.000 \text { ha }\end{array}$ & 7 & $15,6 \%$ & $37.706,99$ & $16,39 \%$ & $\begin{array}{l}\text { PA-1501105-883312332A574C96988AE7BDF1E26CC8, } \\
\text { PA-1501105-5E4EE0A417CD4071944D6DEA4FEEF6E0, } \\
\text { PA-1501105-3963DB9BA950478CB93A4C29B2ABA6B9, } \\
\text { PA-1501105-2B6B2139776F44A19B7050D79F9EF529, } \\
\text { PA-1501105-3F7CBC885C0041AAB8CEEC19550618A9, } \\
\text { PA-1501105-9C22501241C94E2CBB5B0166098F75BC }\end{array}$ \\
\hline $\begin{array}{l}\text { Mais de } \\
10.000 \text { ha }\end{array}$ & 1 & $2,2 \%$ & $153.113,95$ & $66,57 \%$ & PA-1501105-3F0A6CD5001F453DA736EBD56FB493B3 \\
\hline Total & 45 & $100,0 \%$ & $230.015,33$ & $100,00 \%$ & \\
\hline
\end{tabular}

Fonte: Elaboração própria a partir de dados do SICAR-PA. 
Figura 1- Sobreposição de CARs individuais com o CAR coletivo PAE Ilha Cararuá Grande.

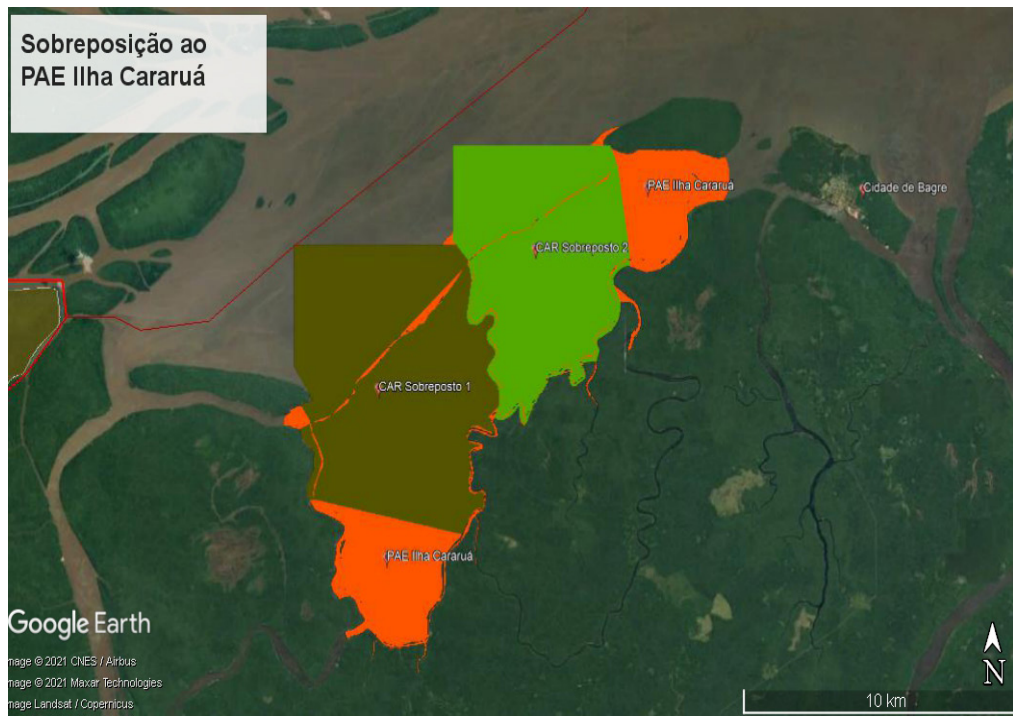

Fonte: Elaboração por Yara Monteiro a partir de dados de CAR, 2021.

Com base nessas informações, a Diretoria do STTR de Bagre protocolou junto à SEMAS um pedido de cancelamento no SICAR-PA (STTR BAGRE, 2019), o qual foi atendido com a suspensão desses cadastros em 19 de maio de 2019 (PARÁ, 2019a; 2019b).

Outro ganho importante desse processo foi o aumento do interesse dos agricultores e agricultoras familiares da região em torno da discussão do CAR, inclusive com a previsão de realização de atividades em campo para registro no módulo Povos e Comunidades Tradicionais (PCT), mas que foram paralisadas devido à pandemia de Covid-19.

\section{Disputa de TERritórios a PARTIR das diferenÇAS de CADASTRO do} CAR E NORMAS AFINS OU CORRELATAS

Para se entender os efeitos das iniciativas gestão florestal e regularidade ambiental sobre o ordenamento territorial do Marajó, é necessário atentar para as contradições entre o que está disposto nas leis n⿳o . 11.284/2006 e 12.651/2012.

A partir da primeira normatização, toda a área natural ou plantada localizada em algum dos biomas brasileiros passou a ser considerada "floresta pública", a qual poderia ser gerida diretamente por entes federativos; concedida para exploração por empresas florestais, nacionais ou estrangeiras; ou ainda destinada para manejo sustentável por comunidades tradicionais (BRASIL, 2006). 
Enquanto a seguida normatização criou um regime jurídico especial, com regras mais flexíveis, a fim de promover a regularização ambiental de imóveis rurais com passivos anteriores a 22 de julho de 2008. Para esse fim, foi estabelecida a adesão compulsória ao CAR e outros instrumentos destinados a auxiliar os produtores rurais na gestão ambiental de propriedades e posses rurais.

Segundo o Art. $6^{\circ}$ do Decreto n⿳. 7.830/2012, “a inscrição no CAR, obrigatória para todas as propriedades e posses rurais, tem natureza declaratória e permanente, e conterá informações sobre o imóvel rural, conforme o disposto no art. 21" (BRASIL, 2012a).

Assim, o CAR passou a ser considerado como uma tecnologia indispensável para a gestão da cobertura florestal no território nacional e uma importante ferramenta de gestão ambiental e fonte de informação para o Programa de Recuperação Ambiental (PRA). Sendo também um condicionante de financiamentos bancários (i.e., Programa Nacional de Fortalecimento da Agricultura Familiar $\bigotimes$ Pronaf), além de requisito para emissão de atestados de circulação de produtos agrícolas e florestais ou até mesmo acesso à benefícios sociais tendo como base a localização geográfica que ele informa.

O seu caráter compulsório e auto declaratório, combinados à ausência de fiscalização sistemática possibilitou com que milhares de imóveis rurais localizados na Amazônia Legal fossem inscritos no SICAR, sendo centenas deles no Marajó, sem necessariamente terem comprovado se havia histórico de ocupação da terra ou se essa inscrição dessa área não incidia sobre floresta pública destinada e já registrada no CNFP.

Muito embora o CAR tenha sido criado como um novo registro destinado monitorar e garantir a execução das políticas ambientais, em inúmeros casos, ele seguiu o caminho da especulação fundiária. Isto porque muitos atores sociais se aproveitaram das disposições e omissões presentes nas normativas para se enquadrarem na política pública e utilizá-la para atendimento de seus interesses pessoais, no caso a apropriação privada de terras públicas. A este respeito afirma Moreira (2016), “o CAR jamais fora concebido como mecanismo fundiário, mas sim como mecanismo de regularização ambiental. Todavia, sempre teve por pressuposto a existência de uma propriedade ou posse válidas sobre as quais incidiria o cadastro. Ocorre, porém, que na prática este pressuposto tem sido deixado de lado e com isto o CAR passa paulatinamente a servir-se de instrumento para grilagem [...]”.

Inicialmente, pode se atribuir essa apropriação ao fato dessa legislação ter sido elaborada por atores sociais que possuíam uma lógica privatista terra e do território. Por isso, este diminuiu os limites ao uso abusivo da propriedade fundiária da terra e aumentou a possibilidade de manter e estender as áreas de cultivo ilegalmente devastadas. 
Desse modo, o NCF estabeleceu o cadastramento compulsório de todos os imóveis rurais no CAR que teria a finalidade de integrar as informações ambientais das propriedades e posses rurais e garantir que fossem registrados o perímetro de cada propriedade existente, bem como suas respectivas RL e APP. Isto ocorreu porque, na elaboração desse instrumento, não havia nenhuma especificação em relação a tipologia das propriedades a serem incluídas no CAR, concebendo-se que todas as formas de propriedade da terra eram obrigadas a se cadastrarem e quando completado o cadastramento, todas as terras rurais do Brasil estariam a ele integradas, excluídas as áreas consideradas urbanas, porque mesmo as urbanas com uso rural estariam sujeitas a esta mesma obrigatoriedade (SOUZA FILHO, 2016).

Neste sentido, o registro do CAR é também obrigatório para os povos e comunidades tradicionais, sendo esta inscrição também regulamentada pela IN no․ 02/2014, em seus Arts. 58 a 60, os quais estabelecem as responsabilidades pelo registro dessas comunidades no CAR, a responsabilização solidária de instituição competente ou entidade representativa no caso de existência de passivo ambiental e os critérios para recuperação ambiental desses passivos, todavia há uma série de questões que dificultam a inscrição dos territórios tradicionalmente ocupados no SICAR.

Esta determinação que se estendeu também sobre os territórios de povos indígenas, quilombolas e tradicionais, não levou em consideração a necessidade de realização de consulta prévia prevista pela Convenção 169 da Organização Internacional do Trabalho (OIT), vem provocando uma série de conflitos e problemas nessas áreas, tais como exposição desses territórios a lógica de imóveis privados, e desconsiderando aspectos tradicionais e coletivos do uso da terra e do manejo da biodiversidade. Seja pela necessidade de se introduzir nesse sistema informações relativas a espaços internos como a RL e a APP. Deste modo, o CAR se encontra em conflito com a visão desses povos e ainda provoca o problema da superposição de cadastros individuais a esses territórios tradicionalmente ocupados

Cabe recordar que, que mais ou menos, no mesmo período em que estavam sendo discutidas as mudanças normativas que deram origem ao CNFP e ao CAR foi editado o Decreto no. 6.040/2007 que institui a Política Nacional de Desenvolvimento. Sustentável dos Povos e Comunidades Tradicionais (PNPCT) (BRASIL, 2007a). A partir dela, o governo federal fortaleceu o entendimento da importância dos chamados "povos da floresta", como atores-chaves na proteção dos recursos naturais.

A despeito disso, povos e comunidades tradicionais, a exemplo dos marajoaras, continuaram com dificuldades para realizar o registro de suas terras, seja pelo conflito entre suas formas de apropriação e uso da terra e o modo como o CAR foi concebido, seja pela situação de exclusão digital vivenciada por várias dessas comunidades. Ademais, continuam também sofrendo o cerco realizado por distin- 
tos atores econômicos interessados na apropriação de terras e a mercantilização da natureza, por meio de cadastros.

\section{CONSIDERAÇões FINAIS}

Sancionado por meio da Lei no. 12.651/2012, que o institui o NCF, o CAR desde a sua concepção foi aclamado como um instrumento capaz de promover não apenas as regularização ambiental das áreas de vegetação nativa das propriedades particulares do país, mas também de proporcionar as condições gerenciais para o combate ao desmatamento nos distintos biomas brasileiros e até mesmo para o atendimento das metas de controle e redução de emissões de gases de efeito estufa previstos no âmbito dos acordos climáticos firmados pelo país.

No entanto, cabe recordar que, embora a ideia de constituição do CAR tenha surgido dentro de um debate sobre as estratégias integradas para conter o avanço dos índices de desmatamento na Amazônia Legal, a sua lógica de normatização e execução acabou conduzindo exatamente ao oposto. Isto ocorre porque a proposta de demarcação georreferenciada das áreas de APPs e RL aparentemente acaba por favorecer a ideia de preservação de apenas uma pequena fração da vegetação nativa existente no interior dos imóveis rurais, e autorizando o corte e a queima de todo o restante.

Considerando ainda que; esta legislação anistiou e impediu que os órgãos ambientais aplicassem quaisquer autuações pelos crimes ambientais após a sanção da lei e até a implantação dos PRAs pelos estados; que a inscrição no CAR é a condição compulsória para a adesão ao PRA; e que o prazo final de realização desse cadastro foi prorrogado inúmeras vezes desde a edição da Lei, prevalece também a ideia de perdão e esquecimento das volumosas e graves infrações ambientais cometidas.

Concebido a partir da lógica privada e individualista, sobretudo do chamado agronegócio, e não contando com a participação na sua concepção e formulação dos povos indígenas e comunidades tradicionais, no seu início o CAR não admitia formas de cadastramento coletivas e hoje, vários anos após esse princípio, muitos gestores e técnicos envolvidos nessa política ainda tem dificuldades em reconhecer e incorporar em seus cadastros, mapeamentos e formas de gestão territorial comunitária.

Finalmente, a despeito das mudanças normativas e dos investimentos técnicos e financeiros realizados, prevalece a sobreposição de cadastros rurais e a desarticulação entre as iniciativas de regularização fundiária e ambiental em curso, o que acaba emperrando as ações de verificação desses cadastros ambientais e potencializando a ocorrência de conflitos pela terra.

\section{Agradecimentos}


Agradecemos à senhora Maria José Souto Maia, Presidente do STTR de Bagre, pela oportunidade de participar dessa experiência de luta pela terra e fazer o seu relato.

\section{REFERÊNCIAS}

ALMEIDA, A. W. B. de. Agroestratégias e desterritorialização: direitos territoriais e étnicos na mira dos estrategistas dos agronegócios. In: (Org.); Capitalismo globalizado e recursos territoriais: fronteiras de acumulação no Brasil contemporâneo. Rio de Janeiro: Lamparina, 2010, p. 101-143.

ANTELO, F.S.F.S. Regularização fundiária na Amazônia: uma análise de políticas de ordenamento fundiário a partir da abordagem cognitiva de políticas públicas. Tese (Doutorado em Ciências Sociais) - Instituto de Ciências Humanas e Sociais, Departamento de Agricultura e Sociedade, Universidade Federal Rural do Rio de Janeiro, Seropédica, RJ, 2018.

ARAÚJO, S.M.G.V. de. Lei de Gestão de Florestas Públicas: polêmicas e perspectivas. Biblioteca Digital da Câmara dos Deputados. Brasília: Câmara dos Deputados, 2008. Disponível em: https://www.researchgate.net/publication/259384882_Lei_ de_Gestao_das_Florestas_Publicas_polemicas_e_perspectivas. Acesso em: 13 jun. 2021.

AZEVEDO, A.A. Legitimação da insustentabilidade? Análise do Sistema de Licenciamento Ambiental de Propriedade Rurais $\square$ SLAPR (Mato Grosso). Tese (Doutorado em Desenvolvimento Sustentável) - Centro de Desenvolvimento Sustentável da Universidade de Brasília, Brasília, DF, 2009.

BARBOSA, H.M. O Programa Bolsa Família e a dinâmica migratória rural: o caso do município de Bagre/Pará. Dissertação (Mestrado em Gestão Pública) - Núcleo de Altos Estudos Amazônicos, Universidade Federal do Pará, Belém, PA, 2016.

BARROS, C.; BARCELOS, I.; GALLO, J.O. As falhas e inconsistências do Cadastro Ambiental Rural. Agência pública, 1 ago. 2016. Disponível em: https://apublica. org/2016/08/as-falhas-e-inconsistencias-do-cadastro-ambiental-rural/. Acesso em: 8 set. 2020.

BRASIL. Casa Civil da Presidência da República. Decreto no. 6.040, de 7 de fevereiro 
de 2007. Institui a Política Nacional de Desenvolvimento Sustentável dos Povos e Comunidades Tradicionais. Diário Oficial (da) República Federativa do Brasil. Brasília, DF, 8 fev. 2007a. Disponível em: http://www.planalto.gov.br/ccivil_03/_ ato2007-2010/2007/decreto/d6040.htm. Acesso em: 14 jun. 2021.

Decreto n⿳o. 6.063, de 20 de março de 2007. Regulamenta, no âmbito federal, dispositivos da Lei no 11.284, de 2 de março de 2006, que dispõe sobre a gestão de florestas públicas para a produção sustentável, e dá outras providências. Diário Oficial (da) República Federativa do Brasil. Brasília, DF, 21 mar. 2007b. Disponível em: http://www.planalto.gov.br/ccivil_03/_ato2007-2010/2007/decreto/ d6063.htm. Acesso em: 14 jun. 2021.

Decreto $n^{\circ}$. 7.029, de 10 de dezembro de 2009. Institui o Programa Federal de Apoio à Regularização Ambiental de Imóveis Rurais, denominado "Programa Mais Ambiente", e dá outras providências. Diário Oficial (da) República Federativa do Brasil. Brasília, DF, 11 dez. 2009a. Disponível em: http://www.planalto.gov.br/ccivil_03/_Ato2007-2010/2009/Decreto/D7029. htm\#: :text=DECRETO\%20N\%C2\%BA\%207.029\%2C\%20DE\%2010\%20DE\% 20DEZEMBRO\%20DE\% 202009.\&text=Institui\%20o\%20Programa\%20Federal\% 20de,\%E2\%80\%9D\%2C\%20e\%20d\%C3\%A1\%20outras\%20provid\%C3\%AAncias. Acesso em: 8 set. 2020.

. Decreto nº. 7.830, de 17 de outubro de 2012. Dispõe sobre o Sistema de Cadastro Ambiental Rural, o Cadastro Ambiental Rural, estabelece normas de caráter geral aos Programas de Regularização Ambiental, de que trata a Lei no 12.651, de 25 de maio de 2012, e dá outras providências. Diário Oficial (da) República Federativa do Brasil. Brasília, DF, 18 out. 2012a. Disponível em: http://www.planalto. gov.br/ccivil 03/ Ato2011-2014/2012/Decreto/D7830.htm\#: :text=Disp\%C3\%B5e \%20sobre\%20o\%20Sistema\%20de,2012\%2C\%20 e\%20d\%C3\%A1\%20outras\% 20provid\%C3\%AAncias. Acesso em: 9 set. 2020.

. Lei n⿳o. 11.284, de 2 de março de 2006. Dispõe sobre a gestão de florestas públicas para a produção sustentável; institui, na estrutura do Ministério do Meio Ambiente, o Serviço Florestal Brasileiro - SFB; cria o Fundo Nacional de Desenvolvimento Florestal - FNDF; altera as Leis nos 10.683, de 28 de maio de 2003, 5.868, de 12 de dezembro de 1972, 9.605, de 12 de fevereiro de 1998, 4.771, de 15 de setembro de 1965, 6.938, de 31 de agosto de 1981, e 6.015, de 31 de dezembro de 1973; e dá outras providências. Diário Oficial (da) República Federativa do Brasil. Brasília, DF, 3 mar. 2006. Disponível em: http://www.planalto.gov.br/ 
ccivil 03/ ato2004-2006/2006/lei/111284.htm. Acesso em: 9 set. 2020.

. Lei no. 11.952, de 25 de junho de 2009. Dispõe sobre a regularização fundiária das ocupações incidentes em terras situadas em áreas da União, no âmbito da Amazônia Legal; altera as Leis nos 8.666, de 21 de junho de 1993, e 6.015, de 31 de dezembro de 1973; e dá outras providências. Diário Oficial (da) República Federativa do Brasil. Brasília, DF, 25 jun. 2009b. Disponível em: http://www.planalto .gov.br/ccivil_03/_Ato2007-2010/2009/Lei/L11952.htm\#: :text=Disp\%C3\%B5e\% 20sobre\%20a\%20regulariza\%C3\%A7\%C3\%A3o\%20fundi\%C3\%A1ria,1973\%3B\% 20e\%20d\%C3\%A1\%20outras\%20provid\%C3\%AAncias. Acesso em: 8 set. 2020.

. Lei no. 12.651, de 25 de maio de 2012. Dispõe sobre a proteção da vegetação nativa; altera as Leis $\mathrm{n}^{\circ}$ s 6.938, de 31 de agosto de 1981, 9.393, de 19 de dezembro de 1996, e 11.428, de 22 de dezembro de 2006; revoga as Leis $\mathrm{n}^{\circ} \mathrm{s} 4.771$, de 15 de setembro de 1965, e 7.754, de 14 de abril de 1989, e a Medida Provisória $\mathrm{n}^{\circ}$ 2.166-67, de 24 de agosto de 2001; e dá outras providências. Diário Oficial (da) República Federativa do Brasil. Brasília, DF, 28 maio 2012b. Disponível em: http://www.planalto.gov.br/ccivil_03/_ato2011-2014/2012/lei/112651.htm. Acesso em: 7 set. 2020 .

Plano de Desenvolvimento Territorial Sustentável do Arquipélago do Marajó. Brasília: CCPR/Gabinete da Governadora do Pará, 2007c.

BRASIL. Fundação Cultural Palmares. Certidões expedidas às Comunidades Remanescentes de Quilombos (CRQ's) atualizada pela Portaria no ${ }^{\circ}$ 104/2016, publicada no DOU de 20/05/2016. Disponível em: http://www.palmares.gov.br/ wp-content/uploads/2016/06/COMUNIDADES-CERTIFICADAS.pdf. Acesso em: 18 jun. 2021.

BRASIL. Instituto Nacional de Colonização e Reforma Agrária. Sistema Nacional de Cadastro Rural: indicadores básicos 2013. Brasília: Incra, 2013. Disponível em: https://www.gov.br/incra/pt-br/acesso-a-informacao/indices_basicos_2013_por_ municipio.pdf. Acesso em: 16 jul. 2021.

BRASIL. Instituto Brasileiro de Geografia e Estatística. Censo Demográfico de 2010. Disponível em: https://censo2010.ibge.gov.br/. Acesso em: 10 set. 2020.

Divisão regional do Brasil em regiões geográficas imediatas e regiões geográficas intermediárias: 2017. Rio de Janeiro: IBGE, 2017. Disponível em: https:// biblioteca.ibge.gov.br/visualizacao/livros/liv100600.pdf. Acesso em: 04 jun. 2021. 
BRASIL. Ministério do Meio Ambiente. Exposição de Motivos (EM/MMA/GM) no. 14, de 16 de fevereiro de 2005. Disponível em: http://www.planalto.gov.br/ ccivil_03/Projetos/EXPMOTIV/MMA/2005/14\%20.htm. Acesso em: 13 jun. 2021.

Sítios Ramsar no Brasil, s/d. Disponível: https://antigo.mma.gov.br/ processo-eletronico/item/8564.html. Acesso em: 18 jun. 2021.

BRASIL. Serviço Florestal Brasileiro. Florestas públicas somam quase 300 milhões de hectares, s/d. Disponível em: http://www.florestal.gov.br/publicacoes/62informacoes-florestais/82-florestas-publicas-somam-quase-300-milhoes-dehectares. Acesso em: 2 out. 2020.

. O que é o Cadastro Ambiental Rural (CAR). 2016. Disponível em: http:// www.florestal.gov.br/cadastro-ambiental-rural. Acesso em: 7 set. 2020.

. Números do Cadastro Ambiental Rural. 2020. Disponível em http://www. florestal.gov.br/numeros-do-car. Acesso em: 7 set. 2020.

CAMPELO, L. Cadastro Ambiental é usado para legalizar grilagem na Ilha de Marajó. Brasil de fato, 12 abril 2017. Disponível em: https://www.brasildefato.com. br/2017/04/12/cadastro-ambiental-e-usado-para-legalizar-grilagem-na-ilha-demarajo/. Acesso em: 7 set. 2020.

. Justiça “atropela” Incra e despeja ribeirinhos assentados no Marajó. Brasil de fato, 21 jun. 2018. Disponível em: https://www.brasildefato.com.br/2018/06/21/ justica-atropela-incra-e-despeja-ribeirinhos-assentados-no-marajo/. Acesso em: 11 set. 2020 .

CHULES, E.L.; SCARDUA, F.P.; MARTINS, R.C.C. Desafios da implementação da política de concessões florestais federais no Brasil. Revista de Direito Econômico e Socioambiental. Curitiba, v. 9, n. 1, p. 295-318, jan./abr. 2018.

EULER, A.M.C.; RAMOS, C.A.P. Nota técnica 05: Marajó conectado: como a internet pode melhorar a vida da juventude marajoara no contexto da pandemia e da bioeconomia. Macapá: Embrapa Amapá, 2021. Disponível em: https://www. infoteca.cnptia.embrapa.br/infoteca/handle/doc/1132328. Acesso em: 16 jun. 2021.

LINS DE GÓIS, S.L. Gestão de florestas públicas na Amazônia Legal: consensos de uma disputa. Tese (Doutorado em Desenvolvimento Sustentável) - Universidade 
de Brasília. Centro de Desenvolvimento Sustentável, Brasília, DF, 2011.

MAPBIOMAS. Cobertura do solo dos municípios do Marajó. 2019. Disponível em http://plataforma.amazonia.mapbiomas.org/map. Acesso em: 18 jun. 2021.

MAPBIOMAS ALERTA. Bagre. 2021. Disponível em https://plataforma.alerta. map biomas.org $/$ mapa? monthRange[0] =2018-11\&monthRange[1]=2021-04\&territoryType $=$ city\&territory $=17666 \&$ territoryIds $[0]=17666 \&$ activeLayers $[0]=$ municipios\&map=-2.436857\%2C-50.730743\%2C9. Acesso em: 18 jun. 2021.

MARTINS, H.; SOUZA Jr., C. Avaliação do desmatamento e do Cadastro Ambiental Rural (CAR) no Pará: bases para o Programa Municípios Verdes. O Estado da Amazônia. Belém: Imazon, 2011.

MOREIRA, E. O Cadastro Ambiental Rural: a nova face da grilagem na Amazônia. Abrampa, 7 jul. 2016. Disponível em: https://abrampa.org.br/abrampa/site/index. php?ct $=$ conteudoEsq\&id=230\&modulo=NOT\%C3\%8DCIA. Acesso em: 8 set. 2020

PACKER, L.A. et al. CAR Pra Quem? Pra Quê? Rio de Janeiro: Fundação Heinrich Böll, 2018. Disponível em: https://br.boell.org/sites/default/files/cartilha_car_web01.pdf. Acesso em: 8 set. 2020.

PARÁ (Governo do). Lei no. 6.963, de 16 de abril de 2007. Dispõe sobre a criação do Instituto de Desenvolvimento Florestal e da Biodiversidade do Estado do Pará IDEFLOR-Bio e do Fundo Estadual de Desenvolvimento Florestal - FUNDEFLOR, e dá outras providências. (Redação dada pela Lei Estadual $n^{\circ}$. 8.096, de $1^{\circ}$ de Janeiro de 2015 e alterações da Lei Estadual no 8.633, de 19 de junho de 2018). Diário Oficial (do) Estado do Pará. Belém, PA, 16 abril 2007. Disponível em: https://ideflorbio. pa.gov.br/wp-content/uploads/2018/07/Lei-Estadual-N\%C2\%BA.-6.963-de-16-deabril-de-2007.pdf. Acesso em: 12 set. 2020.

PARÁ (Governo do). Decreto estadual no. 1148, de 17 jul. 2008. Institui o Cadastro Ambiental Rural - CAR-PA como um instrumento da Política Estadual de Florestas e do Meio Ambiente. Diário Oficial (do) Estado do Pará. Belém, PA, 17 jul. 2008. Disponível em:https://www.semas.pa.gov.br/2008/07/17/9687/. Acesso em: 11 set. 2020.

PARÁ (Governo do). Instituto de Terras do Pará. Título de Reconhecimento de Direito Coletivo. Belém: Iterpa, 2020. Disponível em: http://portal.iterpa. 
pa.gov.br/wp-content/uploads/2021/06/ASSOCIACAO-DE-REMANESCENTESDE-QUILOMBOS-DE-TATITUQUARA-SAO-SEBASTIAO-AJARA-e-BOAESPERANCA-2008-203536.pdf. Acesso em: 18 jun. 2021.

PARÁ (Governo do). Fundação de Amparo a Estudos e Pesquisas do Pará. Anuário Estatístico do Pará 2020. Belém: Fapespa, 2020. Disponível em: http://www.fapespa. pa.gov.br/menu/170. Acesso em: 15 jun. 2021.

PARÁ (Governo do). Secretaria de Estado de Meio Ambiente e Sustentabilidade. Nota técnica no. 19.667/DIGEO/SAGRA/2019. Belém: SEMAS, 30 abril. 2019a

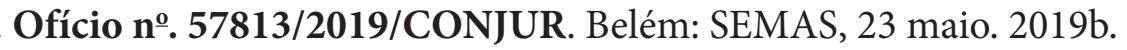

. Sistema do Cadastro Ambiental do Estado do Pará, 2020. Disponível em: http://car.semas.pa.gov.br/\#/. Acesso em: 7 set. 2020.

PIRES, V. Tentativa de regularizar terras com CAR causa polêmica. Instituto Socioambiental. 17 jul. 2017. Disponível em: https://www.socioambiental.org/ pt-br/noticias-socioambientais/tentativa-de-regularizar-terras-com-car-causapolemica. Acesso em: 12 set. 2020.

PIRES, M.O; SAVIAN, G.C.P.S. A implementação da política de regularização ambiental no Novo Código Florestal e as propostas de alteração da Lei no․ 12.651, de 2012. In: SILVA, A.P.M. da; MARQUES, H.R; SAMBUICHI, R.H.R. (Org). Mudanças no código florestal brasileiro: desafios para a implementação da nova lei. Rio de Janeiro: Ipea, 2016, p. 79-106.

RAMOS, P.; FERREIRA, F.; COSTA, A. Marajó: Cobertura do Solo e Ordenamento Territorial. 3 jul. 2020. Disponível em https://www.recantodasletras.com.br/elivros/6994817. Acesso em: 7 set. 2020.

SILVA, D.F. O Cadastro Ambiental Rural (CAR) como instrumento de informação e monitoramento da reserva legal no Estado do Pará. 2015. Dissertação (Mestrado em Direito, Políticas Públicas e Desenvolvimento Regional) - Centro Universitário do Estado do Pará, Belém, PA, 2015.

SOUZA FILHO, C.F.M de. Apresentação: os riscos do Cadastro Ambiental Rural para os povos tradicionais. In: SOUZA FILHO, C.F.M de; ROSSITO, F.D (Org.). 
Estudos sobre o cadastro ambiental rural (CAR) e consulta prévia. Curitiba: Letra da Lei, 2016, p. 7-15.

SOUZA FILHO; C.F.M de; SONDA, C.; LEMOS, A. Cadastro Ambiental Rural (CAR) e povos tradicionais. In: SOUZA FILHO, C.F.M de; ROSSITO, F.D (Org.). Estudos sobre o cadastro ambiental rural (CAR) e consulta prévia. Curitiba: Letra da Lei, 2016, p. 17-34.

SINDICATO DOS TRABALHADORES RURAIS, AGRICULTORES E AGRICULTORAS FAMILIARES DE BAGRE (STT BAGRE). Ofício STTR no. 007/2019. Bagre: STTR Bagre, 18 mar. 2019.

THIOLLENT, M. Metodologia da pesquisa-ação. 18ed. São Paulo: Cortez, 2011

VIEIRA, S.J. Cadastro Ambiental Rural (CAR): aspectos negativos do registro. Migalhas. 4 jul. 2019. Disponível em: https://www.migalhas.com.br/depeso/305656/ cadastro-ambiental-rural-car-aspectos-negativos-do-registro. Acesso em: 9 set. 2020 . 